INTERNATIONAL DESIGN CONFERENCE - DESIGN 2018

https://doi.org/10.21278/idc.2018.0528

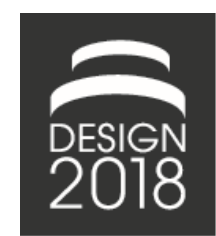

\title{
THE CHALLENGES OF TEACHING SUSTAINABLE SYSTEM DESIGN
}

\author{
A. F. V. Pineda and U. Jørgensen
}

\begin{abstract}
We present the program Sustainable Design Engineering, where Science and Technology Studies theories are a core element among design and engineering approaches. Our main claim is that existing product centred and short-term oriented solution tools and knowledges are inadequate for system design in a sustainable transition perspective. To achieve this goal, design theory and practices need to be further improved to be able to tackle controversies and engage in proposing how to navigate conflicting matters of concern and partial systemic clashes with a long-term scope.
\end{abstract}

Keywords: complex systems, sustainable design, design education

\section{Introduction}

The authors of this paper work at Aalborg University offering the educational program Sustainable Design Engineering. At the same time, we are researchers at the Centre for Design and Innovation for Sustainable Transitions. These two institutional affiliations reveal our normative purposes: we are committed to support processes of transition towards sustainability through design at various scales. Our effort, thus, imply facing several challenges central to the analytical content of this paper. First, that of placing back design as the central object of practice in an engineering education; second, that of aligning seriously the challenge of transition to sustainability essentially requiring paradigmatic systemic changes; and third, understanding that these paradigmatic systemic changes at the same time are social and technological in nature (requiring a socio-technical approach).

The first challenge we face by organizing the curriculum around design projects. Aalborg University is an institution were Project Based Learning is pervasive and a general standard. Therefore, we have been able to structure the undergraduate program around a series of design projects that progress in topics and methodologies. Figure 1 presents the undergraduate program. To the left are the semesters. In the rows are the projects in bright yellow and the courses in white background to the right. In every semester (except the fourth) half of the academic load for the students is a project. Additionally, students follow three courses. It is expected that they will accomplish the same academic learning as a traditional engineering design program, but instead of having six discreet courses (which is the international standard), the students learn through project assignments. It is also desired, though not always achieved, that the topics of the three courses are in line with the aims and content of the project.

The fifth semester is about the Design of Sustainable Systems. Through the project the students learn about systems theories, actor configurations, socio-technical change, the constitution of sustainability in particular solutions, design methods and their limitations and technical knowledge related to the technical systems they decide to focus on (more on this with the example below). The three other courses are: Sustainability, Economy and Politics where they learn and discuss standard literature on sustainability, and then discuss it critically in the context of their project; Fluid Mechanics, that is 
difficult to couple with the project unless the project deals with any kind of fluid; and Applied Statistics, which has the potential of being coupled with the project as systems are only knowable partially and through statistical more than deterministic methods. However, because of the standardisation of general service courses (Wilson et al., 2011), this has not been achieved yet.

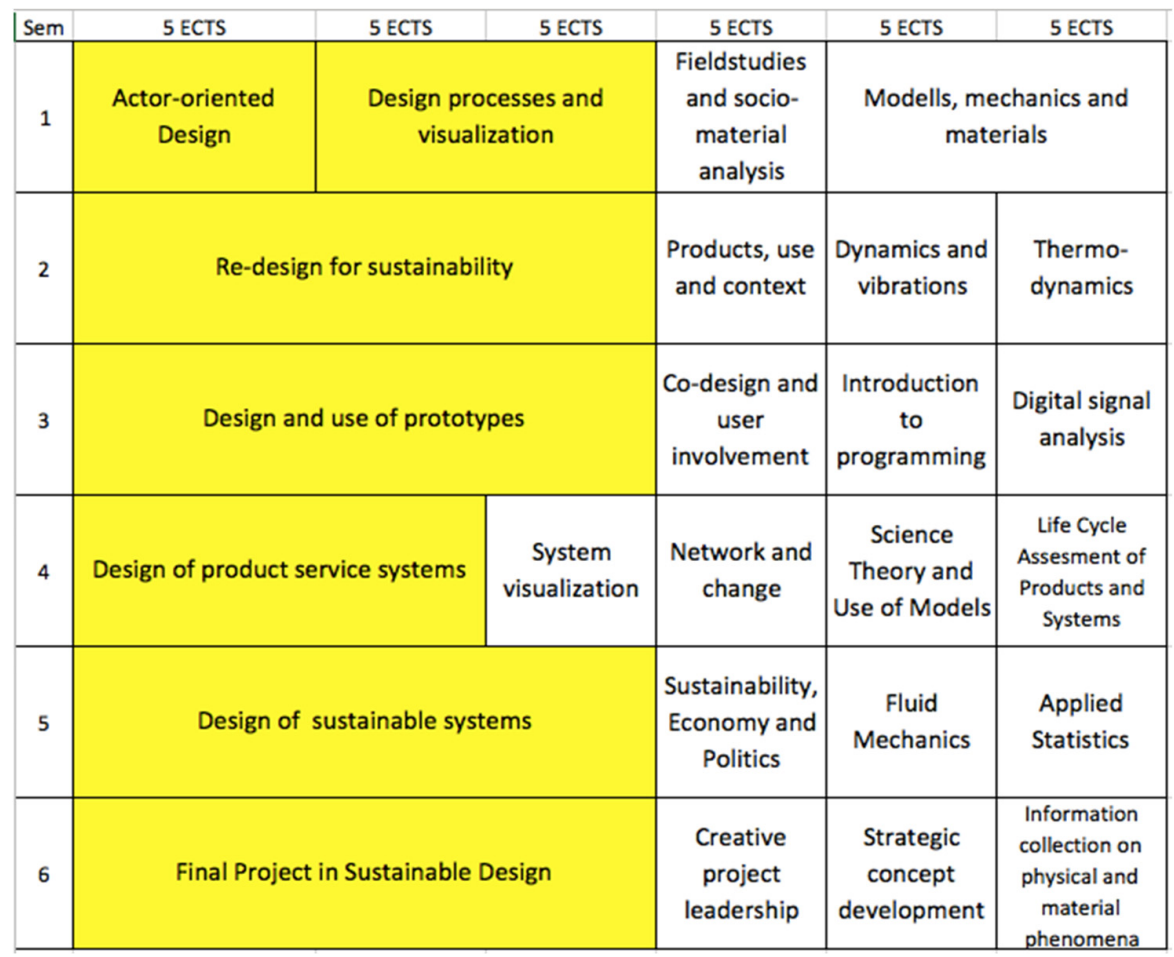

Figure 1. Structure of the BSc in Sustainable Design Engineering

The second challenge we tackle by structuring a progression from projects focussed on product design in the first three semesters, to product related service system and business model design in the fourth semester, to a focus on sustainable system design in the fifth semester. Two core questions to all semester projects are on one hand, how the sustainability framework is applied or discussed in the context of the project. On the other hand, what is defined as the core object of design for each semester. In line with Problem and Project Based Learning principles the projects are developed by the students with supervision by the teaching staff (Barge, 2010). There are only few lectures within the project schedule on issues like systems modelling, implementation and translation processes and governance. This leaves the students to use the bulk of project time to problem identification and to search for the additional knowledge they need to perform the analysis and the synthesis needed to develop a design project. This is a completely different way of learning, which stands in sharp contrast to the established paradigm of educating engineers through a multitude and often disconnected technical courses (and a few courses in social sciences and the humanities), which focus exclusively on small problem-solving exercises where students apply mathematical equations to find a desired unique result (Lucena, 2003).

And for the third challenge, we also assume as a core element of our education, a socio-technical approach (Bijker et al., 1987). Socio-technical theories contribute to design and technology development in three fundamental ways. The first one is by acknowledging that the current knowledge is socially constructed and therefore limited. This opens up for the possibility of training the students in assessing existing knowledge comprehensively to be able to point out to knowledge gaps and even develop new knowledge (Latour, 1987). The second one is acknowledging that all processes exhibit conflicts and controversies at different levels. Therefore, performing design is not about rational application of design methods, but requires understanding controversies, conflicts and misalignments between those who constitute knowledge and technology and intervening on them (Latour, 2005; Storni, 2015). And the third one is that the process of producing technology and knowledge is not fundamentally different than 
any other social process. Put in other words, the fact that design include technologies does not make it a process that is exempted from politics and therefore any proposed design solution, should be able to perform in the political debate that is going to generate (Hansen and Clausen, 2017).

From the above discussion, we want to follow up asking three key questions addressed in this article based on the planning visions and experiences with the fifth semester's focus on sustainable design of systems: (1) what is the design object in projects that tackle sustainable transitions, (2) how is sustainability framed and discussed through these design objects and (3) what knowledge can we build to tackle such systemic design challenges.

\section{The object of design: Systems transitions}

The notion system has been core to many fields of engineering and social sciences Thus, we should define our take on what we understand by using the term system. To start let us present what is not our system approach. We take this step to clarify what kind of system understandings we discard as we find them too limited in relation to our sustainable transition efforts. We do not limit systems to a specific technology like IT systems. Although IT development might be relevant for system design, it is not the main part to take into account. We do not understand system design as robust product design, or in other words, as detailing the scope by looking at products as systems of elements or taking into account as much relationships in a products lifetime as possible like e.g. taken up in a life cycle approach. This relates to our ambition to go beyond product-service systems, which remain trapped in having the products functional services at its centre. Projects aimed at creating new technical energy systems, or transport systems (autonomous vehicles is the most recent hype!), or communication systems, might be very interesting, but when they are framed as pure technical projects it is because a political decision of excluding the influence of relevant actors (including citizens and all kinds of institutions) has already been taken. This does not fit with any kind of serious transition process to sustainability.

As it will become clear from the example presented later in this paper, the kind of systems we work with, go beyond the implicit configuration of client-designer in typical design projects (Ryan, 2014). This happens because the typical actor configuration of systems that are big enough to challenge the existing knowledge paradigms and established institutions begin at the neighbourhood scale. More concretely we tackle systems of water management for climate change rain episodes in a neighbourhood, systems of solid waste collection and reuse for new neighbourhoods, systems of energy (electric and heating) for existing neighbourhoods, or reuse of furniture in long time spans, which require the establishment of systems that support circularity in ways that go beyond something that could be conceptualized looking only at producers and consumers. The type of projects we tackle include a variety of actors like different citizen groups, municipalities, local organizations, regulations, standards, associations, public institutions, private companies, NGOs, grassroots movements, etc.

\section{Sustainability: The challenge of systemic change}

We live in a fundamentally unsustainable world. The current rate of production and consumption on the planet exceeds by far what earth can sustain (Rockström, 2015). And this is happening because we are living, producing, consuming and existing according to the knowledge we have developed until now. The main barrier to fundamentally change this situation lies in the fact that our current knowledge is not suited to substantiated sustainable systems at the planetary level (Vazquez, 2017). Therefore, any kind of effort that claims to be in the road to sustainability, but that does not challenge the existing knowledge and institutional configurations is doomed to fail. Sustainability, true sustainability, strong sustainability (Kuhlman and Farrington, 2010), flourishing (Ehrenfeld, 2008), requires a fundamental paradigm shift in the ways we know, produce, consume and live on the planet. Therefore, a system design approach, with a transition perspective (Geels et al., 2016), should include challenging existing knowledge. The opposite should be avoided basically because it is not possible to apply existing knowledge to achieve sustainability because that knowledge is inappropriate. This requires of those attempting sustainable system design to be able to assess existing knowledge and to challenge it with new ways of world-ing (Vazquez, 2017). Several fields of enquiry like Ecological Economics (Røpke, 2004) can be of inspiration, but for design purposes a theory that is sensitive to actor configurations and to map and understand the work put into making things exist is needed. 


\section{New knowledge: Where to look?}

If we cannot generally trust the solutions and the particular disciplinary knowledge that supports these, how can we then take up sustainable system design challenges? The answer lies in a fundamental conception of what science and knowledge is. Science is not the result of a smooth articulated rational and skilled application of the scientific method (Latour, 1987). Science, and knowledge, is the result of an accomplished social process where politics, power struggles, conflicts and open controversies are dealt with, just like in any other area of human activity. Therefore, the first step, in a sustainable system design process is to abandon the idea of pure, particular authoritative knowledge. Second step, develop and informed critique on existing knowledge. All our existing technical systems might be better than those that existed before (combustion engine cars are better than horses for transport in many ways), but from a sustainability point of view, from the idea of preserving resources, the planet and even humans, the existing systems are not the best ones (note the extreme inefficiencies of motorized transport or its outright threat to human life). Therefore, the need for theories that support critical analyses of the production and constitution of knowledge. Step three, design opens for the possibility of doing projects to explore how things could be arranged in a different way.

This is what design offers to a rich analytical tradition of criticism to technology: the possibility of structured exploration of alternatives. But here it is important to go beyond existing institutional configurations: no matter how well intentioned, sustainable energy, or sustainable transportation, or sustainable health, will always be a limited effort if the frameworks of existing public administration are not challenged. And that is what many of the projects we take up at Aalborg University are so exciting for: mix solid waste management with biogas production and community development; mix heating and energy consumption with public spaces and citizen participation; mix transportation, with public spaces, with climate change mitigation with active citizenship; mix in a meaningful way everything that is now separated by existing institutions, regulations, laws, knowledge and a weak understanding of democracy precisely to explore new ways of being or in other words, new modes of existence (Escobar, 2011; Latour, 2013).

\section{Our tested structure for the 5th semester}

The fifth semester project is structured as pictured in Figure 2:

Socio-technical systems mapping (Hughes, Meadows, Callon, Storni)

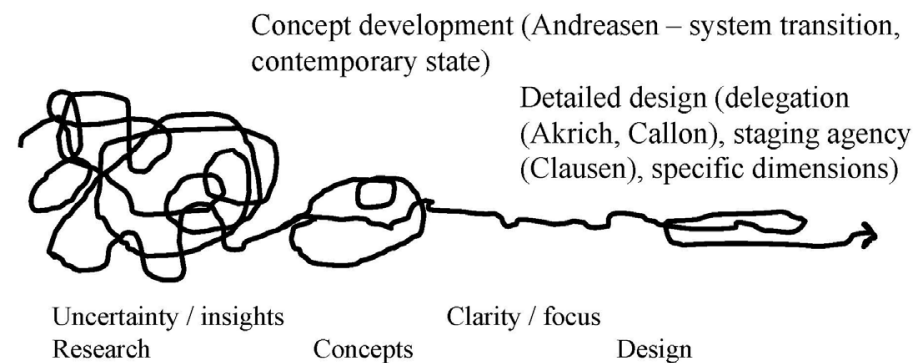

Figure 2. Structure of the fifth semester

The first phase focus on system representation, which we call socio-technical system mapping; the second phase is about developing systemic concepts to focus on whatever challenges the design team chooses to tackle; and the third and final phase is about detailed design. The real period of time the students have for their projects is 3.5 months every fall.

The theoretical resources provided for the process include reading and discussing Meadows (2008) and Hughes (1987) at the beginning of the semester. Meadows book provides a basic language and an understanding of the fundamental concepts and ideas in systems thinking. It also presents some tools that the students might use in their journey like stock and flow diagrams and causal loop diagrams. We insist on being cautious as systems are not knowable but just researchable (Buchanan, 2007). Hughes provides concepts and detailed examples to substantiate the fact that all existing systems are the result of a historical processes and thus attempting to change them or challenge them requires understanding them to be able to interne them. STS theories, and especially ANT, are presented since the beginning of the education. 
Callon (1984) and Storni (2015) are discussed extensively in two courses in the fourth semester to provide the students with the understanding and the tools (visual controversy mapping) to recognize and tackle disagreements, misalignments, conflicts and controversies in design processes. One course is Network and Change which provides the students with the opportunity to learn the fundamentals of Actor Network Theory, Practice Theory and their relation to design. The other course is System Visualisation that deals with methods and techniques to make visual inscriptions. The students also study extensively existing socio-political and socio-economic institutions and systems in the course Sustainability, Economy and Politics as any sustainable System Design project will necessarily challenge existing institutions.

Conceptual design is supported by an extensive discussion on synthesis structured by Mogens Myrup Andreasen and colleagues (Andreasen et al., 2015). The main aspects of this discussion substantiate the solution space as something determined by challenging existing scientific knowledge, bringing in intuitive and other types of knowledge and mapping and understanding thoroughly the configuration of actors that will be involved in the creation and maintenance of any design solution. The source, like the bulk of knowledge in design (Cross and Roy, 1989; Dym and Little, 1994; Ulrich and Eppinger, 2008), is concerned primarily with product design, but offers elements that make it reasonable to adapt them to system design efforts. The main challenge here is to develop concepts that tackle the system level, and do not focus only on one subsystem or element. Additionally, Andreasen and colleagues approach places emphasis on understanding actors' knowledges, capacities and needs in order to be able to propose informed redistribution of agencies. This approach stands in contrast to traditional design and engineering approaches that only place agency on producers and designers and do not take into account users (apart from being passive receivers), actors in charge of maintenance, operation and other related tasks for the functioning of the system and even implicated actors, those affected by the system, but who cannot affect the system (Akrich, 1992).

Detailed design is supported by a critical review of the technical literature the specific system requires and by a socio-technical discussion on delegation and translation. Any given system is a geography of responsibility: some actors have the responsibility of doing something to make a given system or practice exist (Callon, 1984; Akrich, 1992). Sustainable solutions might require a re-distribution of that responsibility sometimes even challenging existing regulations (local, regional, national and/or supranational), institutionalized division of labour (among government sectors for example) and or historical roles (for instance of patients being passive in medical treatments). To understand how these processes of delegation occur in an implicit or explicit fashion the contributions of Akrich (1992), Callon (1984) and Storni (2015) are key. Akrich's concepts of script, inscription, description, re-inscription and prescription provide a language to analyse what is intended with a design and how to reshape it. Callon (1984) provides analytical and visual tools, the sociology of translation, to unpack the processes of delegation of agency to human and non-human actors, or in other words, what is expected from each actor and how those expectations are met. In this process of delegation of agency, the phases of recruitment and consolidation of support networks include a plan for implementation where the risk of single actors including the technical elements not performing as expected is used to assess the robustness, options for realisation and stability of the outlined design solutions are tested. Storni (2015) reflects on the role of the designers as agonistic Prometheans not providing the final answer but facilitating the process of development of new knowledge and circulating it among all actors to make possible democracy in design processes.

\section{Example of a student project}

During the second semester of 2016 students developed four projects. Here we present one of them to illustrate the type of decisions the students take and the difficulties they face. The project in question dealt with the planning of a new neighbourhood that was to be built in the island of Amager, about 3 $\mathrm{km}$ from the city centre of Copenhagen as part of a long-term development of Ørestad, a new part of Copenhagen (Majoor, 2008).

Ørestad is a green field development under the responsibility of the developer 'By og Havn' (in English: City and Harbour) which is owned by the state of Denmark and the city of Copenhagen and has been in charge of the main developments in the harbour areas in the recent past. Planners from this organization approached the university and offered to collaborate with the students. The point of departure was the following: we, they said, normally do things in a particular way because of resource constrains and the 
pace of our work, we want you to help us think how we could do things differently and especially in a sustainable way. In particular, they referred to the waste management systems of the neighbourhoods recently developed in Copenhagen. The standard system installed was a central sucking solid waste system operated by a private supplier. They were aware of the shortcomings of the system including it being a system that requires a lot of energy to run. Additionally, a central sucking station makes difficult separation of waste at the source and makes user participation impossible.

The students set out to work in this project and gathered information on: the existing typical solution installed in recent neighbourhoods; new waste collecting systems installed in Denmark and Sweden; policies and plans from the municipality of Copenhagen (which exhibits contradictory aims focusing on one hand in building one of the biggest solid waste burners of Scandinavia and on the other rolling out an ambitious plan of separating waste at the source to enhance recycling of separate fractions); regulations at the local, city, national and EU level; user attitudes towards solid waste and recycling possibilities; expert knowledge and attitudes; and the characteristics of the new neighbourhood to be built. They particularly noted the relationship between separating at the source and transportation of separated fractions. The more fractions separated the more transportation is needed to remove the waste. More fractions also require more space locally for temporal accumulation of quantities worth transporting. This they illustrated in Figure 3.

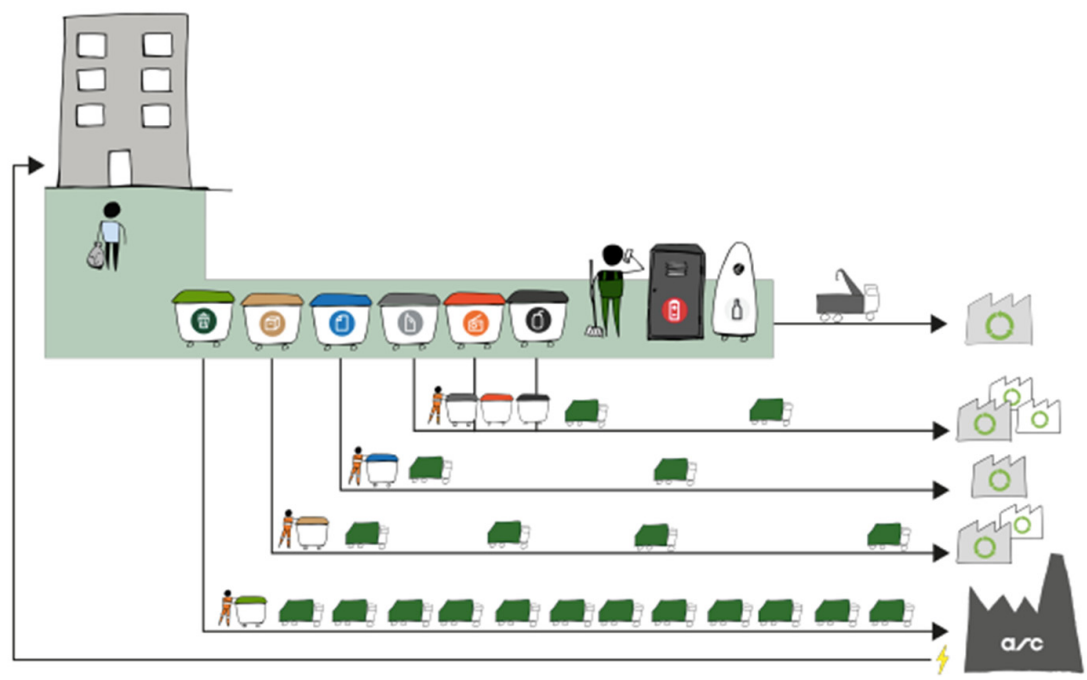

Figure 3. Relation of fractions to transport in the example

Early in the process they found out that the biggest waste fraction in a normal apartment in Copenhagen is the biological fraction which includes all organic waste coming out of the kitchen $(45 \%)$. Consequently, one of the first challenges was to decide whether the system they were designing was a system to handle all the solid waste produced in the new neighbourhood, or if they could narrow the objective to handle and reuse the organic fraction only. They finally chose the latter framing which is a pure designer choice. This was a decision based on the knowledge they had acquired and on an assessment of the resources in time they had to deliver the project, or in other words, a situation of partial knowledge and great uncertainty. The fact that designers make decisions and that in our program they have to do so, stands in sharp contrast with normal engineering education where students normally do not take any decision, but are trained only to calculate results on a given technical problem using established quantitative methods (Lucena, 2003).

Based on the knowledge they had accumulated and the vision of sustainability they were striving for they defined the objective of their project to be: "Develop a system for the new neighbourhood Ørestad Fælled Kvarteret, which creates value for the neighbourhood and its inhabitants by making solid waste a visible resource. The system will meet the desire for transport reduction within the neighbourhood, it will be coupled with the type of habitational units proposed (apartments only) and make possible the use of waste as a resource on site. It will also support the generation of a sense of community and belonging among inhabitants". 
With this as their system objective they defined a list of requirements and criteria, and proceeded to define some concept alternatives to meet them. At this stage, the students struggled with the existing literature which is very detailed in design methods and tools in relation to product design and product service systems (Cross and Roy, 1989; Dym and Little, 1994; Ulrich and Eppinger, 2008). One challenge they had to overcome was that of resisting the temptation of focusing on one material element that resembled a product or a closed technical system (the central sucking station for instance) which would fit best with the existing literature. Therefore, all the elements presented in the requirements and criteria had to be systemic and this was a permanent challenge.

At the stage of concept development, they proposed alternatives presented in Figure 4.

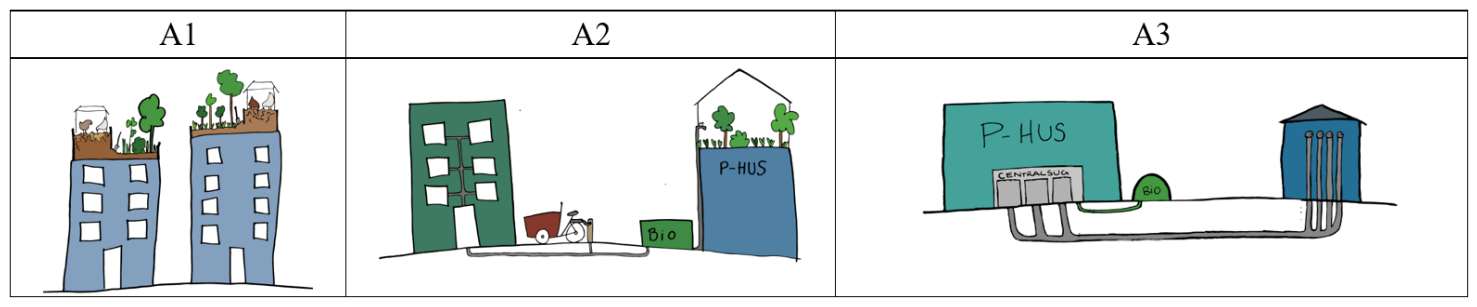

Figure 4. Concepts considered for the design

The three elements of the figure illustrate: composting only on site for reuse in green roofs (A1); reusing organic waste to produce bio-gas and compost on site (A2); and making biogas on site only (A3). These alternatives drew inspiration from experiments in Denmark on smaller rural communities, ecovillages, green roofs and gardens and the fact that the new neighbourhood was to be built in a former natural reserve and it would have been contiguous to the remaining of the natural reserve. The design alternatives were assessed with participation from the planners of 'By og Havn'. Through several design games (Brandt, 2006), the students tested how the different alternatives were in line or not with the general discourse of the developing company, their plans and ideas, and the planners own ideas, which did not necessarily were in line with their employers. They discovered for instance, that 'By og Havn' was quite interested in generating local community activities around the functioning of the neighbourhood to strengthen ownership over common facilities. They also noted that the existing plans at that stage included three parking buildings, which were to be built and ran by 'By og Havn' and which they wanted to use for other purposes than just having cars parked there. And finally, they noted the high value allocated to any community activities in the common roofs and basements of the parking buildings.

After considering the three alternatives and estimating quantities of solid waste, times of digestion, compost production, stock management and other aspects the students selected the alternative 2 to recover and use as much of the biological waste as possible on site. Only after this selection was made, were they in a position to be able to dimension the expected flows in the solution selected. Figure 5 below shows that on a yearly basis it was expected that 5.300 inhabitants would produce 2.120 tons of waste, of which 392 tons were biological waste -to be processed on site- and 1.728 other type of solid waste - to be transported away. The 392 of biological waste had to be complemented with 241,6 tons of structure (branches and other biological waste to guarantee air flow through the waste, otherwise it is just a packed semisolid wet mass that is impossible to oxygenate), to produce $27.056 \mathrm{~m} 3$ of methane, that could be used in an electric generator to produce $81.168 \mathrm{kWh}$ of electricity. This electricity could partially be used to run the central sucking station and could also generate $162,339 \mathrm{kWh}$ of heat to be used in the greenhouses on top of the three shared parking houses. The composted mass that comes out of the biogassificator (368 tons) could also be used as compost in the greenhouses.

It was a surprise to notice that the selected solution required importing structure from outside the neighbourhood in order to support the biogasification process, as this was in contradiction with the stated goal of transport reduction. And that the energy produced by the projected biogas unit would not be enough to drive the central sucking station. These were pieces of knowledge that only appeared in the detailed design phase. In a real project the iterative process would use these as inputs to refine the whole design. I order to tackle these surprises it would be desirable to perform a risk analysis, but until now, unfortunately, this has not been included in the scope of the projects. 
Most importantly the students found that such a solution required a number of changes in the existing relationships among involved actors. In the existing systems, a user normally selects at the source in four fractions (paper, carton, plastic and the rest). The rest can be delivered either personally or by a shut to the central sucking system. The other fractions are delivered in person to the containers in the building. All these fractions are collected separately by the municipality in separate trucks. In these systems, there is no room for separating the organic fraction and the waste just disappears from the user's life as soon as she takes it out of her apartment: legally the municipality of Copenhagen becomes the owner of the waste. By contrast, the solution proposed by the design team states that the organic fraction can be separated at the source. The central sucking system has the capacity of sucking different fractions at different times during the week. The organic fraction is not delivered to the municipality, but all the other fractions are. Instead it is used on site to feed the biogassification unit installed in the basement of one of the three parking houses in the neighbourhood. The by-products of this last process are then used accordingly to fuel a heating system, transport units and finally as fertilizer for the green roof, which in turn is driven by the community of neighbours. In this case, the organic fraction contributes to a building of a local community. In this scenario, it is the neighbourhood who owns the organic waste fraction and uses it as a resource.

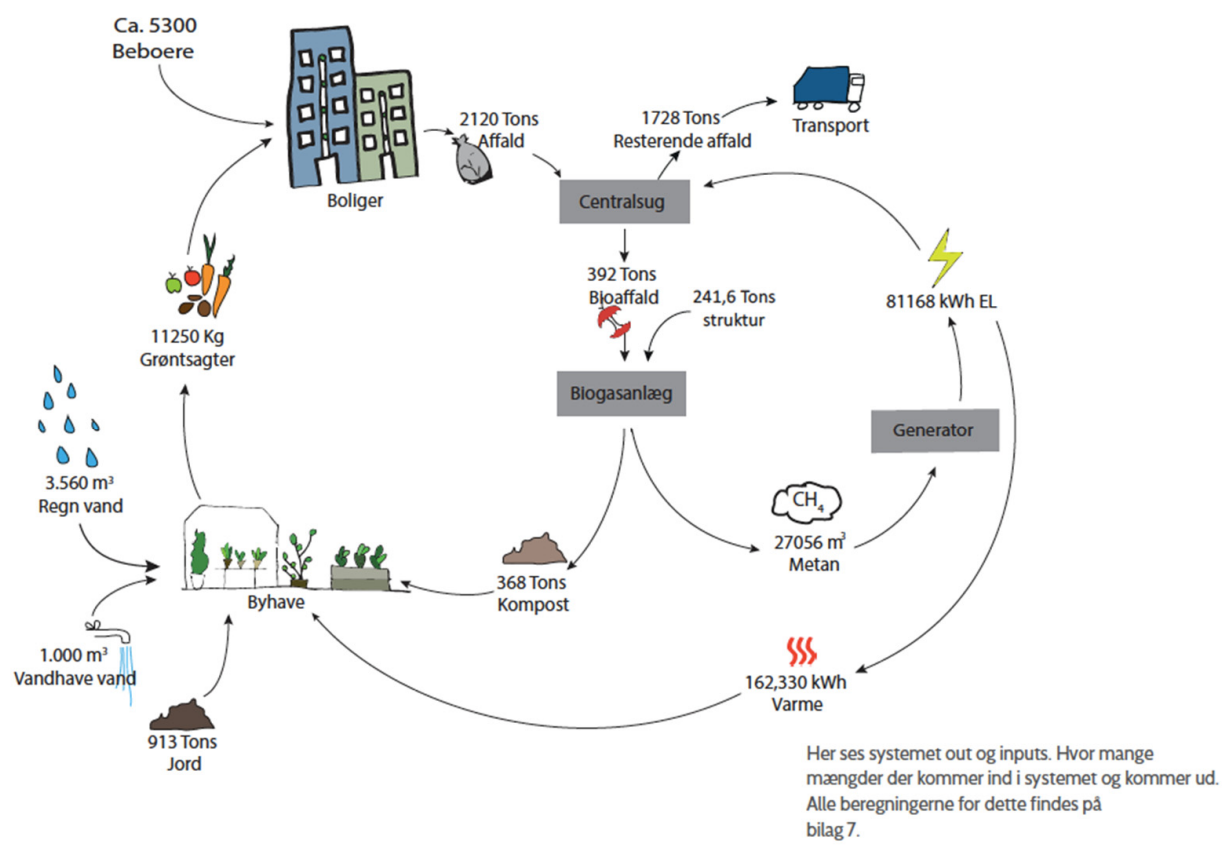

Figure 5. Preliminary dimensioning of the proposed system

\section{Conclusion}

This example illustrates the three key aspects discussed in this paper: the unit of design, designing for sustainability and creating knowledge. First, the unit of design does not fit well into the dominant literature that focus on product design and product-service design. It is also not one of the established systems of the current knowledge division of labour: it is not just a solid waste system, it is not just a solid waste local collection system (central sucking), it is not just a built neighbourhood. It is a particular combination of all these, including how to produce a system that supports community development. The unit of design then fluctuates according to knowledge, project ambitions and the particular solution proposed: it is an assemblage (Latour, 2005).

Second, the project does not frame sustainability in a specific way beforehand. It is part of the project to study and define in which specific ways the issues of resource use, resource conservation, circularity, social relations, environmental concerns are framed in the solution. In this sense sustainability is not a predetermined criterion based on existing limited knowledge: it is not about assessing how the solution complies with the existing DNGB standards in Denmark (Sand et al., 2012). The project itself is an opportunity to 
further discuss what sustainability means and how it can be achieved through system design projects in a particular actor configuration: how sustainability is being materialised in the assembling process.

Third, the design students researched extensively on existing knowledge and challenged it with the proposal of a new solution. Urban biogas production is a non-discussion among current solid waste developers and managers. However, in the context of this project, that became a possibility and one that challenges not only existing knowledge as written in textbooks and scientific articles, but also as attitudes and implicit and explicit beliefs among expert practitioners in the field of solid waste. The design project is critical of existing knowledge.

All these considerations can only be possible by acknowledging that a design process is not a linear, neat and rational process of applying existing knowledge to produce a new material arrangement. It is about messing up with existing knowledge and practices and ways of doing things; it is about understanding how actors go about their routines in relation to solid waste; it is about diving into conflicting views of what is a problem and what is a solution. For this purpose, the traditional narrow instruments of engineering and design as they are taught in traditional programs are not enough: no single method or mathematical model, no matter how systemic it is, can deliver the solution (Hughes, 1998; Geels et al., 2016). The social sciences are also inadequate as they have traditionally ignored materiality (Latour, 1996). Therefore, we, as system builders of this program in Sustainable Design Engineering, have decided to make STS knowledge and more specifically, Actor-Network Theory, a core element in the education: because it tackles controversies explicitly and centrally; because it approaches all actors impartially and symmetrically, not only as active designers and passive users; and because it provides the critical edge necessary to put into question existing knowledges and, if not the tools, at least some guidelines as to how to develop new knowledge.

In line with (Willis, 2017), we propose that system design with a transition perspective as an emerging professional practice should 'capture the extent of divestments needed for a significant cultural shift toward sustainment' (p.70). This requires opening up to the controversies and the politics that entail a fundamental criticism to current existing knowledge, technologies and patterns of production and consumption. The claim here is that this can be achieved by design, but only if design is upgraded from a mere short-term product centred design practice to a focus on design processes that reflect the controversies and engage in proposing how to navigate in a field of conflicting matters of concern and partial systemic clashes with a long-term scope. These entails: dissociating, de-scribing, and critically dismantling the current systems as materialised in everyday object-systems of production and consumption and the corresponding knowledges that support them. This also entails taking transition processes as clashes of partial system orders and the complexity resulting from these seriously, and tackling that complexity by reducing it at first and then increasing it through the design process (Nowotny, 2005). A system design process is thus a systematic attempt to reduce complexity by producing multiple mappings and descriptions at first. Then is about conceptualizing different solutions that exist at the systemic and inter-systemic level, not at the level of components or subsystems. And when a concept is selected is about describing it, structuring it, prototyping it and most importantly circulating and exposing it to different actors to test it. This could provide the opportunity to expanding its complexity in order to become a real alternative to existing systemic arrangements.

\section{Acknowledgment}

Special acknowledgements to the teaching team of Sustainable Design Engineering at Aalborg University. A previous version of this paper focusing on the role of Sociotechnical Theories only appeared in the Chilean journal Diseña in Spanish and English (Pineda and Jørgensen, 2018).

\section{References}

Akrich, M. (1992), "The description of technical objects", In: Bijker, W. and Law, J. (Eds.), Shaping technology/building society: Studies in sociotechnical change, MIT Press, Cambridge, MA, pp. 205-224.

Andreasen, M.M., Hansen, C.T. and Cash, P. (2015), Conceptual Design: Interpretations, Mindset and Models, Springer International Publishing, Cham. https://doi.org/10.1007/978-3-319-19839-2

Barge, S. (2010), Principles of Problem and Project Based Learning: The Aalborg PBL model, Aalborg University.

Bijker, W.E., Hughes, T.P. and Pinch, T.J. (1987), The Social Construction of Technological Systems: New Directions in the Sociology and History of Technology, MIT Press, Cambridge, MA. 
Brandt, E. (2006), "Designing exploratory design games: a framework for participation in Participatory Design?", Proceedings of the ninth conference on Participatory design: Expanding boundaries in design, ACM, pp. 57-66.

Buchanan, R. (2007), "Strategies of design research: Productive science and rhetorical inquiry", In: Michel, R. (Ed.), Design Research Now, Birkhäuser Basel, pp. 55-66. https://doi.org/10.1007/978-3-7643-8472-2_4

Callon, M. (1984), "Some elements of a sociology of translation: domestication of the scallops and the fishermen of St Brieuc Bay", The Sociological Review, Vol. 32 No. S1, pp. 196-233. https://doi.org/10.1111/j.1467954X.1984.tb00113.x

Cross, N. and Roy, R. (1989), Engineering design methods, Wiley, New York.

Dym, C.L. and Little, P. (1994), Engineering design, University Press.

Ehrenfeld, J. (2008), Sustainability by design: A Subversive Strategy for Transforming Our Consumer Culture, Yale University Press, New Haven, CT, USA.

Escobar, A. (2011), "Sustainability: Design for the pluriverse", Development, Vol. 54 No. 2, pp. 137-140. https://doi.org/10.1057/dev.2011.28

Geels, F.W., Berkhout, F. and van Vuuren, D.P. (2016), "Bridging analytical approaches for low-carbon transitions", Nature Climate Change, Vol. 6 No. 6, pp. 576-583. https://doi.org/10.1038/nclimate2980

Hansen, P.R. and Clausen, C. (2017), "Management Concepts and the Navigation of Interessement Devices: The Key Role of Interessement Devices in the Creation of Agency and the Enablement of Organizational Change", Journal of Change Management, Vol. 17 No. 4, pp. 1-23. https://doi.org/10.1080/14697017.2017.1286515

Hughes, T.P. (1987), "The evolution of large technological systems", In: Bijker, W.E., Hughes, T.P. and Pinch, T.J. (Eds.), The Social Construction of Technological Systems: New Directions in the Sociology and History of Technology, MIT Press, Cambridge, pp. 51-82.

Hughes, T.P. (1998), Rescuing Prometheus, Pantheon Books, New York.

Kuhlman, T. and Farrington, J. (2010), "What is sustainability?” Sustainability, Vol. 2 No. 11, pp. 3436-3448. https://doi.org/10.3390/su2113436

Latour, B. (1987), Science in action: How to follow scientists and engineers through society, Harvard University Press.

Latour, B. (1996), Aramis, or, The love of technology, Harvard University Press, Cambridge, MA.

Latour, B. (2005), Reassembling the social: An introduction to actor-network-theory, Oxford University Press.

Latour, B. (2013), An inquiry into modes of existence, Harvard University Press.

Lucena, J.C. (2003), "Flexible engineers: History, challenges, and opportunities for engineering education", Bulletin of Science, Technology \& Society, Vol. 23 No. 6, pp. 419-435. https://doi.org/10.1177/0270467603259875

Majoor, S. (2008), "Progressive planning ideals in a neo-liberal context, the case of Ørestad Copenhagen", International Planning Studies, Vol. 13 No. 2, pp. 101-117. https://doi.org/10.1080/13563470802291978

Meadows, D.H. (2008), Thinking in systems: A primer, Chelsea Green Publishing.

Nowotny, H. (2005), "The increase of complexity and its reduction: Emergent interfaces between the natural sciences, humanities and social sciences", Theory, Culture \& Society, Vol. 22 No. 5, pp. 15-31. https://doi.org/10.1177/0263276405057189

Pineda, A.F.V. and Jørgensen, U. (2018), "Sustainable System Design at Aalborg University, Denmark", Diseña, Vol. 12, pp. 126-149.

Rockström, J. (2015), Bounding the planetary future: Why we need a great transition, Great Transition Initiative.

Røpke, I. (2004), "The early history of modern ecological economics”, Ecological Economics, Vol. 50 No. 3, pp. 293-314. https://doi.org/10.1016/j.ecolecon.2004.02.012

Ryan, A. (2014), “A Framework for Systemic Design”, FormAkademisk, Vol. 7 No. 4, pp. 1-14. https://doi.org/10.7577/formakademisk.787

Sand, H., Hjorth Lorenzen, K. and Burgos Nittegaard, C. (2012), Survey of green legislation and standards in the construction area in the Nordic countries, Nordic Innovation Publication.

Storni, C. (2015), "Notes on ANT for designers: ontological, methodological and epistemological turn in collaborative design", CoDesign, Vol. 11 No. 3-4, pp. 166-178. https://doi.org/10.1080/15710882.2015.1081242

Ulrich, K.T. and Eppinger, S.D. (2008), Product design and development, McGraw-Hill, New York.

Vazquez, R. (2017), "Precedence, Earth and the Anthropocene: Decolonizing design", Design Philosophy Papers, Vol. 15 No. 1, pp. 77-91. https://doi.org/10.1080/14487136.2017.1303130

Wilson, R., Georgakis, S. and Hu, X. (2011), "Meeting the challenges of electrical engineering service courses", Australasian Journal of Engineering Education, Vol. 17 No. 2, pp. 91-100. https://doi.org/10.1080/22054952.2011.11464062

Dr. Andres Felipe Valderrama Pineda, Assistant Professor

Aalborg University, Development and Planning

A C Meyers Vænge 15, 2300 Copenhagen S, Denmark

Email: afvp@plan.aau.dk 